\title{
Assessment of anger, depression symptoms, offence-related shame and guilt levels in women patients with migraine
}

\author{
Ender Kaya ${ }^{\circledR}$, Onur $^{\text {Akan²}}{ }^{\circledR}$
}

${ }^{1}$ Spec. Dr. University of Health Sciences, Okmeydani Education and Research Hospital, Department of Psychiatry, Istanbul - Turkey ${ }^{2} \mathrm{Spec}$. Dr. University of Health Sciences, Okmeydani Education and Research Hospital, Department of Neurology, Istanbul - Turkey

\begin{abstract}
Objective: Many psychological factors have an effect on the formation and course of migraine disease. The aim of this study is to assess the levels of anger, offence-related guilt and shame, and depression of female migraine patients and the correlation of these feelings with each other.

Method: Our study included 50 patients attending the headache clinic with migraine diagnosis according to the diagnostic criteria of the International Classification of Headache Disorder 2004 and 40 control subjects. Participants completed a sociodemographic form, Offence-Related Shame and Guilt Scale (ORSGS), State-Trait Anger Expression Inventory (STAEI), and Beck Depression Inventory (BDI).

Results: Members of the migraine patient group were found to have significantly higher scores for the guilt and shame dimensions of the ORSGS, the BDI, and the trait anger and anger-out subdimensions of the STAEI compared to the control group. The scores for the shame dimension showed strong positive correlation with the anger-in subdimension.

Conclusion: Migraine patients experience anger more intensely than healthy individuals. Emotions of offence-related guilt and shame may be associated with migraine headaches. Assessing guilt and especially feelings of shame in the psychological treatment of migraine is considered important.
\end{abstract}

Keywords: Anger, female, guilt, migraine, shame

\section{INTRODUCTION}

Migraine is a frequently observed recurrent, unilateral, complex, multifactorial, hereditary neurovascular disorder that may cause incapacity (1).

Nearly $15 \%$ of the world population experience migraine. In the United States of America (USA), every year $18 \%$ of women and $6 \%$ of men are recorded as migraine patients. The lifelong risk is $43 \%$ for women and $18 \%$ for men. The lifelong social risk in Europe is between 12 and $28 \%$. Every year, $14-35 \%$ of women and 6-15\% of men experience migraine (2).

Studies researching the correlation between migraine and anger indicated that migraine patients experience more feelings of anger (3), have anger control problems (4), and they are especially characterized by high levels of internally directed anger (5). At the same time, migraine patients were identified to have higher levels of internally

How to cite this article: Kaya E, Akan O. Assessment of anger, depression symptoms, offence-related shame and guilt levels in women patients with migraine. Dusunen Adam The Journal of Psychiatry and Neurological Sciences 2020;33:358-365.

Correspondence: Ender Kaya, Spec. Dr. University of Health Sciences, Okmeydani Education and Research Hospital, Department of Psychiatry, Istanbul - Turkey

E-mail: enderkaya76@yahoo.com

Received: June 09, 2020; Revised: July 27, 2020; Accepted: October 08, 2020 
directed and externally directed anger than healthy persons (6). Interestingly, another study found externally directed anger levels to be greater among treated and healthy migraine patients (7).

Loker (8) stated that individuals making a wrong choice may become angry with themselves after conscious assessment and then suppress the negative feelings caused by this offence into the subconscious. Additionally, the half-head headache in migraine was interpreted as sending a subconscious message indicating that the offending individual is half-wit, acts semi-blindly, and harms him- or herself. Personal offences causing feelings of shame and guilt are problematic feelings perceived as a result of experiencing failures or behavior contrary to social norms. The negative mood caused by these feelings acts as a punishment for immoral behavior. Feelings of shame focus on a person's identity, while feelings of guilt focus on behavior (9). To the best of our knowledge, there is no study in the literature assessing the feelings of guilt and shame experienced in relation to offence among migraine patients.

Wolf et al. (10) described migraine patients as having perfectionist, rigid, orderly, ambitious, and competitive personality traits. This definition played a pioneering role in studies determining the personality traits of migraine cases. Patients with migraine and stress-type headache are associated with neuroticism (11), while these patients experience more depression compared to healthy controls (12). Additionally, migraine patients were identified to have higher scores for the "neurotic three" (hypochondriasis, hysteria, and depression) on the MMPI (Minnesota Multiphasic Personality Inventory) (13). The personality profile of patients with migraine who are more prone to suppress their emotions (14) is an important determinant of the disease (15). On the other hand, it has been reported that personality traits of migraine patients with markedly affected social and professional functionality are a strong predictor of migraine (16).

A review of the literature has revealed several studies emphasizing the importance of the association of migraine with anger. However, to our knowledge, there is no research that has assessed offence-related shame and guilt among patients with migraine. The relation between migraine and the emotions of guilt and shame in women, who are generally more prone to sense these feelings than men, is a subject of debate $(17,18)$. Similarly, our literature search did not reveal any study that focused on the association between these three emotions and somatic signs of neurological disease. Thus, to our knowledge, this is the first study that has been designed to fill the gap described above and may thus contribute to the understanding of the psychopathology underlying migraine.

In the present study, it was aimed to compare the level of guilt or shame and the level and expression of anger in migraine patients with the control group. The other objective of this study is to investigate the association between anger expression and offencerelated guilt and shame.

For this purpose, the following hypotheses have been put forward:

H1: Patients with migraine experience higher levels of offence-related shame and guilt compared to the control group.

H2: Migraine patients experience a higher level of anger than the control group.

H3: The anger expression styles of migraine patients are related with offence-related shame and guilt.

\section{METHOD}

\section{Sample}

The study sample included 50 female migraine patients with previous or new diagnosis by a neurologist according to the diagnostic criteria of the International Classification of Headache Disorder 2004 who attended the SBU Okmeydani Education and Research Hospital's headache clinic. A total of 40 healthy female control subjects with similar age, educational level, and marital status as the patients were included in the control group. This study was conducted between February 20 and May 15, 2020. The control group comprised healthy individuals with no headache complaints or mild headaches occurring less than 4 times per year with no other bodily or physical complaints and no previous neurologic or psychiatric treatment.

Individuals forming the control group were selected among the hospital attendants of patients treated at hospital departments other than psychiatry and neurology and from our hospital staff. Patients with migraine and healthy controls were evaluated by an expert psychiatrist using Structured Clinical Interview for DSM-IV Axis I Disorders (SCID-I).

Inclusion criteria for the migraine patient group were an age between 18 and 60 years, being female, literate, and volunteering for participation in the study. Exclusion criteria were having any neurologic or chronic disease apart from migraine, previously diagnosed psychiatric disease, acute psychosocial stressors that might affect test results, antidepressant use, and presence of mental disability. 
All patients consecutively admitted to the neurology outpatient clinic who were diagnosed with migraine were invited to participate in this study. Among the patients who agreed to participate, those who met the inclusion criteria and none of the exclusion criteria were first administered an informed consent form, followed by a data collection form and the forms administered by the interviewer, in a quiet and suitable venue. Eight patients were excluded from this study, including some who were using antidepressants, had recently lost a relative, or who were illiterate.

Both groups completed the sociodemographic data form, Offence-Related Shame and Guilt Scale (ORSGS), State-Trait Anger Expression Inventory (STAEI), and Beck Depression Inventory (BDI). This study was conducted in compliance with the Helsinki Declaration; the participants were informed about this study and gave verbal and written consent.

\section{Measures}

Sociodemographic Form: This form included sociodemographic data like age, sex, marital status, and educational level of individuals participating in the study.

Structured Clinical Interview for the DSM-IV Axis-1 Disorders (SCID-1): This is a semi-structured interview form that was developed by First et al. (19) in 1997 to assess and diagnose axis-1 disorders according to DSM-IV. Our study employed the Turkish version of the form, for which validity and reliability studies had been performed by Corapcioglu et al. (20).

Offence-Related Shame and Guilt Scale (ORSGS): The original scale was developed by Wright and Gudjonsson (21). Comprising 10 items, the scale uses a 7-point Likert-type scale for scoring ("1" not at all - "7" completely). The scores that can be obtained from the scale range from 7 to 70 . The internal consistency reliability coefficient of the scale is very good with 0.87 for the shame subscale and 0.86 for the guilt subscale. The Turkish adaptation of the scale was shown to be valid and reliable for the ORSGS levels of individuals (22).

State-Trait Anger Expression Inventory (STAEI): This measure was developed by Spielberger (23); validity and reliability studies for the Anger Expression Scales (AngerEx) in Turkey were performed by Ozer (24). The scale measures feelings of anger and forms of expression with a 4-point Likert-type scale comprising 34 questions. It contains 4 subdimensions: trait anger, anger-in, angerout, and anger control. Adaptation studies for the scale established criterion-related validity and performed factor analysis. Reliability studies found item-total score correlations between 0.14 and 0.56 , with Cronbach's alpha internal consistency coefficients from 0.73 to 0.84 (25). Additionally, Cronbach's alpha internal consistency coefficients for the sample group in this research were determined as 0.72 for trait anger, 0.60 for anger control, 0.59 for anger-out and 0.48 for anger-in.

Beck Depression Inventory (BDI): This instrument developed by Beck et al. (26) measures the bodily, emotional, and cognitive symptoms observed in depression. It is a self-report scale containing 21 symptom categories. The highest score that can be obtained is 63. A higher total score shows greater severity of depression. A validity and reliability study of the BDS in Turkey was performed by Hisli (27).

\section{Statistical Analysis}

Statistical analyses used the Number Cruncher Statistical System (NCSS) 2007 package (Kaysville, Utah, USA). When assessing study data, descriptive statistical methods (mean, standard deviation, median, frequency, proportion, minimum, maximum) were applied. For quantitative data, Student's t-test was used to compare variables with normal distribution in two groups and the Mann-Whitney $U$ test when comparing non-normally distributed variables in the two groups. Pearson's chi-square test and Fisher-Freeman-Halton test were used to compare qualitative data. For analysis of correlations between quantitative variables, Pearson correlation analysis and Spearman correlation analysis were carried out. Significance was assessed at a level of $\mathrm{p}<0.05$. Multiple linear regression analysis was used to determine whether migraine patients' anger expression styles predicted guilt and shame.

\section{RESULTS}

Our study included 50 migraine patients and 40 controls. All of the migraine cases included in our study were female with a mean age $39.30 \pm 9.67$ years, while the mean age in the control group was $37.75 \pm 8.89$ years $(t=-0.783 ; p=0.436)$. There were no significant differences between migraine patients and control group regarding education and marital status (Table 1).

Data obtained from the ORSGS, BDI and STAEI scales for the migraine patients and the healthy control group were analyzed. The migraine patients were found to have statistically significantly higher scores for the guilt and shame dimensions of the ORSGS compared to the control group $(\mathrm{p}<0.01)$. The migraine patient group members had significantly higher points for the BDI $(p<0.01)$ and STAEI trait anger and anger-out subscales 
Table 1: Distribution of demographic characteristics according to group

\begin{tabular}{|c|c|c|c|c|c|c|c|c|c|}
\hline & \multicolumn{3}{|c|}{ Control } & \multicolumn{3}{|c|}{ Migraine } & \multirow[b]{2}{*}{$\mathbf{p}$} & \multirow[b]{2}{*}{$\chi^{2} / \mathrm{t}$} & \multirow[b]{2}{*}{ SD } \\
\hline & Min.-Max. & Mean & SD & Min.-Max. & Mean & SD & & & \\
\hline \multirow[t]{2}{*}{ Age } & $22-57$ & 37.75 & 8.89 & $20-57$ & 39.30 & 9.67 & ${ }^{\mathrm{a}} 0.436$ & -0.783 & 88 \\
\hline & $\mathbf{n}$ & $\%$ & & $\mathbf{n}$ & $\%$ & & & & \\
\hline \multicolumn{10}{|l|}{ Education status } \\
\hline Primary/High school & 9 & 22.5 & & 9 & 18 & & ${ }^{c} 0.632$ & 0.226 & 1 \\
\hline University & 31 & 77.5 & & 41 & 82 & & & & \\
\hline \multicolumn{10}{|l|}{ Marital status } \\
\hline Single & 15 & 37.5 & & 19 & 38 & & b0.961 & 0.002 & 1 \\
\hline Married & 25 & 62.5 & & 31 & 62 & & & & \\
\hline
\end{tabular}

aStudent's t-Test, 'bearson's Chi-Square Test, 'Fisher-Freeman-Halton Test

compared to the control group $(\mathrm{p}<0.05)$ (Table 2$)$. Correlation analyses investigated the correlations between the guilt and shame dimension scores on the ORSGS, BDI scores, and STAEI subscale scores between migraine patients and healthy control group. For BDI scores, there was a weak level of positive correlation with the shame dimension and a weak level of negative correlation with the anger control subscale $(\mathrm{r}=0.330 ; \mathrm{r}=-0.303)$.

The guilt dimension scores on the ORSGS had a positive strong correlation with shame scores $(r=0.728)$, a weak positive correlation with trait anger scores $(\mathrm{r}=0.306)$, and a moderate positive correlation with anger-in scores $(r=0.433)$. For the shame dimension, there was a weak positive correlation with the trait anger subscale $(r=0.397)$, a strong positive correlation with the anger-in subscale $(\mathrm{r}=0.618)$, and a weak positive correlation with the anger-out subscale $(r=0.302)$ (Table 3).Multiple regression analysis performed to predict the guilt dimension found that of the four dimensions, only anger-in was a significant predictor. These dimensions explain $18 \%$ of the guilt size variance. In multiple regression analysis to predict the size of shame, again only anger-in was found to be a significant predictor. These dimensions explain $39 \%$ of the variance in size (Table 4 ).

\section{DISCUSSION}

The aim of this study was to compare offence-related guilt and shame, anger, and depression scores of migraine patients with healthy controls. The ORSGS score of the migraine patients was significantly higher than that of the healthy controls. Significant correlations were found between ORSGS score and trait anger-anger expression scores.

Headache is a common symptom that shows association with psychiatric disorders affecting the quality of life and may be triggered by an accompanying psychiatric disorder, personality traits, and stress factors (28). The risk of depression is increased in migraine patients (16). As expected, in our study migraine

Table 2: Assessment of scale points according to group

\begin{tabular}{|c|c|c|c|c|c|c|c|c|}
\hline & \multicolumn{6}{|c|}{ Group } & \multicolumn{2}{|c|}{ Test value } \\
\hline & \multicolumn{3}{|c|}{ Control $(n=40)$} & \multicolumn{3}{|c|}{ Migraine $(n=50)$} & \multirow[b]{2}{*}{$\mathbf{t}$} & \multirow[b]{2}{*}{$\mathbf{p}$} \\
\hline & Min.-Max. & Mean & SD & Min.-Max. & Mean & SD & & \\
\hline Beck Depression Inventory & $2-16$ & 8.33 & 3.38 & $5-38$ & 14.74 & 7.89 & -4.118 & ${ }^{d}<0.001$ \\
\hline \multicolumn{9}{|c|}{ Offence-Related Shame and Guilt Scale } \\
\hline Guilt Dimension & $10-31$ & 21.35 & 5.35 & $11-35$ & 25.38 & 6.94 & -3.023 & ${ }^{\mathrm{a}} 0.003$ \\
\hline Shame Dimension & $7-32$ & 17.65 & 6.27 & $7-34$ & 23.14 & 7.81 & -3.699 & ${ }^{a}<0.001$ \\
\hline \multicolumn{9}{|l|}{ State-Trait Anger Scale } \\
\hline Trait Anger & $14-31$ & 20.95 & 4.18 & $13-38$ & 23.92 & 7.01 & -2.494 & ${ }^{\mathrm{a}} 0.015$ \\
\hline Anger-In & $9-29$ & 16.63 & 3.97 & $9-28$ & 18.26 & 4.37 & -1.837 & ${ }^{\mathrm{a}} 0.070$ \\
\hline Anger-Out & $11-25$ & 16.20 & 3.43 & $11-28$ & 18.10 & 4.47 & -2.215 & ${ }^{\mathrm{a}} 0.029$ \\
\hline Anger Control & $14-31$ & 22.13 & 3.77 & $12-33$ & 21.44 & 4.99 & 0.741 & ${ }^{\mathrm{a}} 0.461$ \\
\hline
\end{tabular}

aStudent's t-Test, 'Mann-Whitney U Test 
Table 3: Assessment of scale points according to group

\begin{tabular}{|c|c|c|c|c|c|c|}
\hline & $\begin{array}{c}\text { Beck Depression } \\
\text { Inventory }\end{array}$ & Guilt Dimension & Shame Dimension & Trait Anger & Anger-In & Anger-Out \\
\hline \multicolumn{7}{|c|}{ Guilt Dimension } \\
\hline$r$ & $0.204^{e}$ & - & & & & \\
\hline $\mathrm{p}$ & $0.053^{*}$ & - & & & & \\
\hline \multicolumn{7}{|c|}{ Shame Dimension } \\
\hline$r$ & $0.273^{e}$ & $0.707^{f}$ & - & & & \\
\hline$p$ & 0.009 & $\leq 0.001$ & - & & & \\
\hline \multicolumn{7}{|c|}{ Trait Anger } \\
\hline$r$ & $0.314^{e}$ & $0.336^{f}$ & $0.415^{f}$ & - & & \\
\hline $\mathrm{p}$ & 0.003 & $\leq 0.001$ & $\leq 0.001$ & - & & \\
\hline \multicolumn{7}{|c|}{ Anger-In } \\
\hline$r$ & $0.286^{e}$ & $0.344^{f}$ & $0.572^{f}$ & $0.457^{f}$ & - & \\
\hline $\mathrm{p}$ & 0.006 & $\leq 0.001$ & $\leq 0.001$ & $\leq 0.001$ & - & \\
\hline \multicolumn{7}{|c|}{ Anger-Out } \\
\hline$r$ & $0.285^{e}$ & $0.083^{f}$ & $0.308^{f}$ & $0.671^{f}$ & $0.327^{f}$ & - \\
\hline $\mathrm{p}$ & 0.006 & $0.439^{*}$ & 0.003 & $\leq 0.001$ & 0.002 & - \\
\hline \multicolumn{7}{|c|}{ Anger Control } \\
\hline$r$ & $-0.307^{e}$ & $-0.067^{f}$ & $-0.183^{f}$ & $-0.377^{f}$ & $-0.028^{f}$ & $-0.397^{f}$ \\
\hline $\mathrm{p}$ & 0.003 & $0.528^{*}$ & $0.085^{*}$ & $\leq 0.001$ & $0.796^{*}$ & 0.001 \\
\hline
\end{tabular}

${ }^{e} \mathrm{r}=$ Spearman's correlation coefficient, ${ }^{\mathrm{f}} \mathrm{r}=$ Pearson correlation coefficient, ${ }^{*} \mathrm{p}>0.05$

Table 4: Multiple regression analysis results of anger dimensions scores that predict guilt and shame scores

\begin{tabular}{|c|c|c|c|c|c|c|}
\hline Dependent variable & Predictors & B & SD & Beta & $\mathbf{t}$ & $\mathbf{p}$ \\
\hline \multirow[t]{4}{*}{ Guilt Dimension } & Trait Anger & 0.262 & 0.171 & 0.265 & 1.528 & 0.133 \\
\hline & Anger-In & 0.601 & 0.223 & 0.379 & 2.700 & $<0.010$ \\
\hline & Anger-Out & -0.394 & 0.264 & -0.254 & -1.491 & 0.143 \\
\hline & Anger Control & -0.177 & -0.213 & -0.127 & -0.831 & 0.410 \\
\hline \multicolumn{7}{|l|}{$R=0.502 R^{2}=0.252$} \\
\hline \multirow[t]{4}{*}{ Shame Dimension } & Trait Anger & 0.083 & 0.165 & 0.075 & 0.503 & 0.617 \\
\hline & Anger-In & 1.026 & 0.215 & 0.575 & 4.772 & $<0.001$ \\
\hline & Anger-Out & 0.123 & 0.255 & 0.070 & 0.482 & 0.632 \\
\hline & Anger Control & -0.265 & 0.206 & -0.170 & -1.288 & 0.204 \\
\hline
\end{tabular}

patients' depression scores were found to be significantly higher compared to healthy individuals. The depression scores of patients were $14.7 \pm 7.8$, indicating that they experienced mild levels of depression (29).

Migraine patients in our study had higher trait anger scores than healthy people, again as expected. This result shows that migraine patients experience more feelings of anger, which is similar to findings in the literature (30).

Internally-directed anger was shown to be a possible predictive factor for migraine alone (5). However, contrary to this observation, in our study externally- directed anger scores were higher than in healthy individuals. This finding contradicts the consensus about suppressed anger in migraine patients reported in the literature, emphasizing the fact that migraine patients may sometimes suppress their anger, while occasionally they may express their anger externally. However, the reason for the identification of mild levels of depression in our patients may be related to more external expression of anger.

Though it is reported that migraine disease may be associated with feelings of guilt and shame (31), no study was encountered that investigated the correlation 
of guilt/shame feelings with offence in migraine patients. A study in prisoners researched the relationship of offence-related guilt and shame feelings with somatization. A correlation was only found between shame and somatization (32). This study showed that the ORSGS may assess subconscious defense mechanisms. In addition to these findings, Tangney reported that somatization was correlated with both of these feelings but more with shame (33). In addition, guilt and shame are negative emotions that evoke strong aversive feelings and psychological pain (34).

In our study, the guilt and shame scores related to offence in migraine patients were identified to be significantly higher compared to healthy controls. A sensitive point of our study is that feelings of guilt and shame are affected by the severity of depression. However, the mild levels of depression among patients are a desired result. Hence, considering that depression severity increases levels of guilt and shame (35), our study may be considered to show that mild levels of depression have limited effect on guilt and shame levels. As a result, in our study it can be said that guilt and shame levels were assessed more in relation to personality traits rather than depression. As the suppressed feelings of migraine patients cause headache with psychosomatic mechanisms (36), the high levels of feelings of guilt and shame in our patients may increase the level of migraine headache via somatization. In other words, the half-head headache observed in migraine may be a subconscious message with the thought that the patient is "acting like a half-wit" after offences. Similarly, eye pain may be a subconscious message that "you can't see what's happening in front of you, end this!" (8).

Gender differences regarding shame and guilt are not just founded on results from self-report-based scales. Studies representing real shame and guilt experiences obtained similar results. In a study with children aged 2.5-5 years, Alessandri and Lewis (37) revealed that girls displayed more shame behavior (collapsed body, dipped head, etc.) compared to boys in situations of failure. In a study of children newly beginning to walk, researchers observed that girls displayed more behavior representing shame (avoiding behavior, etc.) than boys after breaking toys. The results were contradictory in relation to guilt behavior (38).

Feelings of guilt are linked to constructive reactions like compensatory behavior. By contrast, feelings of shame are associated with psychological adjustment problems like depression. While feelings of guilt are directed toward the behavior perceived as offensive by a person, feelings of shame are directed toward the person's self (39). Similarly, in our study, the shame scores had a positive correlation with depression scores, which may show that feelings of shame target the self. Tangney et al. (33) attributed the fact that the feeling of guilt is not related to psychological problems, in these studies, the feeling of shame and guilt were evaluated together. In other words, a tendency toward guilty feelings without a feeling of shame may not be related with psychological symptoms in some situations.

Guilt scores in our study were identified as having a positive correlation with trait anger and anger-in scores. In addition, the regression analysis applied determined that the anger-in dimension was a predictor of the guilt dimension, which appears to be related to a mechanism of internalizing anger by not blaming others for negative experiences but undertaking responsibility for the offensive behavior (40).

Lutwak et al. (41) found a positive correlation between the tendency toward feelings of shame and internalized anger and a negative correlation between the tendency toward feelings of guilt and externalized anger. In our research, the strong positive correlation between shame scores and anger-in scores was identified with no correlation with anger-out scores. In addition, regression analysis found that the anger-in dimension was a strong predictor of the shame dimension. This result appears to show that migraine patients internalize anger related to disappointments occurring with offence, which negatively affects the self and may impact the severity of the shame feeling.

Fedewa et al. (42) revealed that negative perfectionism has a positive significant correlation with feelings of both guilt and shame. Given that migraine patients may display perfectionist personality traits (10), the high levels of guilt and shame in migraine patients in our study compared to healthy controls are thought to be evidence for perfectionist personality traits of patients. Further, Lutwak and Ferrari (43) show women reporting feelings of shame and guilt at higher rates than men. Additionally, feelings of shame in women are loaded with both selfcritical cognition and perfectionism, and this perfectionism is especially associated with sociallydetermined perfectionism.

However, the "neurotic three" personality trait of hypochondriasis (13) identified in migraine patients was found to be correlated with feelings of guilt, shame, and anger. In our study, which supports this correlation, 
the high levels of guilt, shame, and anger feelings in migraine patients may be related to hypochondriac personality traits.

An important limitation of this study is that cases were not controlled for depression. Low patient numbers, inclusion of female cases only in the study group, and the use of scales to screen for psychiatric symptoms are other limitations of our research. It is not possible to make inferences about general society, given that women have a greater tendency to feel shame and guilt compared to men (17). Another limitation is that patients have mild depressive symptoms. One of the important limitations of such studies, when considering the comorbidity of migraine and depression, is to find migraine patients without depression. It is difficult to predict the effects of migraine medications used by the patients diagnosed with migraine before on our present research. It would be unethical to conduct a study while stopping these patients' medications, which poses an inherent limitation for studies on migraine. Another limitation is the failure to assess clinical features such as duration of migraine, pain intensity, and pain frequency among the psychometric parameters that have been studied.

In the light of these results, our study emphasizes that female patients with migraine may experience anger and feelings of guilt and shame related to offence intensely. It seems important to assess feelings of guilt and shame in addition to anger in psychotherapy to be implemented within the psychological dimension of migraine treatment. There is a need for studies assessing the correlation between migraine and feelings especially of shame among female migraine patients. Furthermore, fMRI studies on shame and guilt discovered perfusion changes in the prefrontal cortex, temporal-parietal cortex, and limbic areas (44), but in migraine, those changes were more common in the hypothalamus, thalamus, basal ganglia, and limbic cortex areas (45). While our findings show a relationship between guilt/ shame and migraine psychologically, adding neuroimaging studies may be interesting.

\begin{tabular}{|c|c|c|}
\hline \multicolumn{2}{|c|}{ Contribution Categories } & Author Initials \\
\hline \multirow{3}{*}{ Category 1} & Concept/Design & E.K., O.A. \\
\hline & Data acquisition & O.A. \\
\hline & Data analysis/Interpretation & E.K., O.A. \\
\hline \multirow{2}{*}{ Category 2} & Drafting manuscript & E.K. \\
\hline & Critical revision of manuscript & E.K. \\
\hline Category 3 & Final approval and accountability & E.K. \\
\hline \multirow{2}{*}{ Other } & Technical or material support & $\mathrm{N} / \mathrm{A}$ \\
\hline & Supervision & $\mathrm{N} / \mathrm{A}$ \\
\hline
\end{tabular}

Ethics Committee Approval: Before the study, both groups provided voluntary consent forms and were provided with detailed information about the study. The study was approved by the Ethics Committee of SBU Okmeydani Education and Research Hospital (18.2.2020/48670771-514.10/40).

Informed Consent: Written informed consent obtained.

Peer-review: Externally peer-reviewed.

Conflict of Interest: The authors have no conflict of interest to declare.

Financial Disclosure: There was no funding for this work.

\section{REFERENCES}

1. Headache Classification Subcommittee of the International Headache Society. The international classification of headache disorders: 2nd edition. Cephalalgia 2004;24(Suppl.1):9-160.

2. Idiman F. Last 40 years in headaches: In Bicakci S, Ozturk M, Ucler S, Karli N, Siva A (editors). Current approaches to diagnosing and treating headaches - practices of the turkish neurology association's working group on headache. Istanbul: Galenos Publishinghouse, 2018; 10. (Turkish)

3. Materazzo F, Cathcart S, Pritchard D. Anger, depression, and coping interactions in headache activity and adjustment: a controlled study. J Psychosom Res 2000; 49:69-75. [CrossRef]

4. Perozzo P, Savi L, Castelli L, Valfrè W, Lo Giudice R, Gentile S, et al. Anger and emotional distress in patients with migraine and tension-type headache. J Headache Pain 2005; 6:392-399.

5. Nicholson RA, Gramling SE, Ong JC, Buenaver L. Differences in anger expression between individuals with and without headache after controlling for depression and anxiety. Headache 2003; 43:651-663. [CrossRef]

6. Celik DB, Arkar H, Idiman F. Anger and temperament and character characteristics in patients with migraine headache. Turkish Journal of Clinical Psychiatry 2010; 13:23-35. (Turkish)

7. Boyle S, Church II WT, Byrnes E. Migraine headaches and anger. Best Pract Ment Health 2005; 1:47-58.

8. Loker A. Dreams, migraine, neuralgia. Istanbul: Altan Loker Publishing, 1993; 175-181.

9. Tangney J. P. Shame and guilt in young adulthood: a qualitative analysis. Arlington VA: The Meetings of the American Psychological Society; 1989.

10. Wolff HG. Personality features and reactions of subjects with migraine. Arch Neurol Psychiatry 1937; 37:895-921. [CrossRef]

11. Cao M, Zhang S, Wang K, Wang Y, Wang W. Personality traits in migraine and tension-type headaches: a five-factor model study. Psychopathology. 2002; 35:254-258. [CrossRef]

12. Ashina S, Bendtsen L, Buse DC, Lyngberg AC, Lipton RB, Jensen R. Neuroticism, depression and pain perception in migraine and tension-type headache. Acta Neurol Scand 2017; 136:470-476.

13. Merikangas KR, Stevens DE, Angst J. Headache and personality: results of a community sample of young adults. J Psychiat Res 1993; 27:187-196. [CrossRef] 
14. Passchierl J, Goudswaard P, Orlebeke JF, Verhage F. Migraine and defense mechanisms: psychophysiological relationships in young females. Soc Sci Med 1988; 26:343-350. [CrossRef]

15. Luconi R, Bartolini M, Taffi R, Vignini A, Mazzanti L, Provinciali $\mathrm{L}$, et al. Prognostic significance of personality profiles in patients with chronic migraine. Headache 2007; 47:1118-1124. [CrossRef]

16. Abbate-Daga G, Fassino S, Lo Giudice R, Rainero I, Gramaglia $\mathrm{C}$, Marech L, et al. Anger, depression and personality dimensions in patients with migraine without aura. Psychother Psychosom 2007; 76:122-128. [CrossRef]

17. Harder DW. Shame and guilt assessment, and relationships of shame- and guilt-proneness to psychopathology: In Tangney JP, Fischer KW (editors). Self-conscious Emotions. The Psychology of Shame, Guilt, Embarrassment, and Pride. New York: The Guilford Press 1995, 368-392.

18. Fischer AH, Rodriguez Mosquera PM, van Vianen AE, Manstead AS. Gender and culture differences in emotion. Emotion 2004; 4:87-94. [CrossRef]

19. First MB, Spitzer RL, Gibbon M, Williams JBW. Structured Clinical Interview for DSM-IV Clinical Version (SCID-I/CV, Version 2.0). New York: New York State Psychiatric Institute, 1997.

20. Corapcioglu A, Aydemir O, Yildiz M, Esen A, Koroglu E. Structured Clinical Interview for DSM-IV Axis I Disorders (SCID-I) Clinical Version. Ankara: HYB Publishing, 1999. (Turkish)

21. Wright K, Gudjonsson GH. The development of a scale for measuring offence-related feelings of shame and guilt. J Forens Psychiatry Psychol 2007; 18:307-316. [CrossRef]

22. Saricam H, Akin A, Cardak M. The study on the validity and reliability of the Turkish form of Offence-related Feelings of Shame and Guilt Scale. Civil Academy Journal of Social Sciences 2012; 10:235-247. (Turkish)

23. Spielberger CD, Jacobs G, Russell S, Crane RS. Assessment of anger: the state-trait anger scale: In Spielberger CD, Butcher JN (editors). Advances in Personality Assessment. Second ed. Hillsdale NJ: Erlbaum, 1983, 159-187.

24. Ozer AK. A pilot study for trait anger (T-Anger) and anger expression (AngerEX) scales. Turkish Journal of Psychology 1994; 9:26-35. (Turkish)

25. Savasir I, Sahin NH. Assessment in cognitive-behavioral therapies: frequently used scales. Ankara: Turk Psikologlar Dernegi Yayinlari, 1997.

26. Beck AT, Ward CH, Mendelson M, Mock J, Erbaugh J. An inventory for measuring depression. Arch Gen Psychiatry 1961; 4:561-571. [CrossRef]

27. Hisli N. A reliability and validity study of Beck Depression Inventory in a university student sample. Turkish Journal of Psychology 1989; 7:3-13. (Turkish)

28. Kaplan H, Sadock BJ. Clinical psychiatry. Philadelphia: Lippincott Williams and Wilkins, 2004.

29. Beck AT, Steer RA, Brown GK. Manual for the Beck Depression Inventory-II. San Antonio, TX: Psychological Corporation, 1996.
30. Eckhardt CI, Deffenbacher JL. Diagnosis of anger disorders: In Kassinove $\mathrm{H}$ (editor). Anger disorders: definition, diagnosis, and treatment. Washington, DC: Taylor \& Francis 1995, 27-48.

31. Haan, J. Migraine and metaphor: In Bogousslavsky J, Dieguz S (editors). Literary medicine: brain disease and doctors in novels, theatre and film. Basel: Karger, 2013, 126-135. [CrossRef]

32. Kovács Z, Kun B, Griffiths MD, Demetrovics Z. A longitudinal study of adaption to prison after initial incarceration. Psychiatry Res 2019; 273:240-246. [CrossRef]

33. Tangney JP, Wagner P, Fletcher C, Gramzow R. Shamed into anger? The relation of shame and guilt to anger and self-reported aggression. J Pers Soc Psychol 1992; 62:669-675. [CrossRef]

34. Carnì S, Petrocchi N, Del Miglio C, Mancini F, Couyoumdjian A. Intrapsychic and interpersonal guilt: a critical review of the recent literature. Cogn Process 2013; 14:333-346. [CrossRef]

35. Kim S, Thibodeau R, Jorgensen RS. Shame, guilt, and depressive symptoms: a meta-analytic review. Psychol Bull 2011; 137:6896. [CrossRef]

36. Lake AE 3rd, Rains JC, Penzien DB, Lipchik GL. Headache and psychiatric comorbidity: historical context, clinical implications, and research relevance. Headache 2005; 45:493-506. [CrossRef]

37. Alessandri SM, Lewis M. Differences in pride and shame in maltreated and nonmaltreated preschoolers. Child Dev 1996; 67:1857-1869. [CrossRef]

38. Barrett KC, Zahn-Waxler C, Cole PM. Avoiders versus amenders: implications for the investigation of guilt and shame during toddlerhood? Cogn Emot 1993; 7:481-505. [CrossRef]

39. Tangney JP. Self-conscious emotions: the self as a moral guide: In Tesser A, Stapel DA, Wood JV (editors). Self and motivation: emerging psychological perspectives. Washington DC: American Psychological Association, 2002, 97-117. [CrossRef]

40. Tangney JP, Wagner P, Gramzow R. Proneness to shame, proneness to guilt, and psychopathology. J Abnorm Psychol 1992; 101:469-478. [CrossRef]

41. Lutwak N, Panish JB, Ferrari JR, Razzino BE. Shame and guilt and their relationship to positive expectations and anger expressiveness. Adolescence 2001; 36:641-653.

42. Fedewa BA, Burns LR, Gomez AA. Positive and negative perfectionism and the shame/guilt distinction: Adaptive and maladaptive characteristics. Pers Individ Differ 2005; 38:16091619. [CrossRef]

43. Lutwak N, Ferrari JR. Moral affect and cognitive processes: differentiating shame from guilt among men and women. Pers Individ Differ 1996; 21:891-896. [CrossRef]

44. Michl P, Meindl T, Meister F, Born C, Engel RR, Reiser M, et al. Neurobiological underpinnings of shame and guilt: a pilot fMRI study. Soc Cogn Affect Neurosci 2014; 9:150-157. [CrossRef]

45. Maniyar FH, Sprenger T, Monteith T, Schankin C, Goadsby PJ. Brain activations in the premonitory phase of nitroglycerintriggered migraine attacks. Brain 2014; 137:232-241. [CrossRef] 